\title{
The Mathematics of Grace Murray Hopper
}

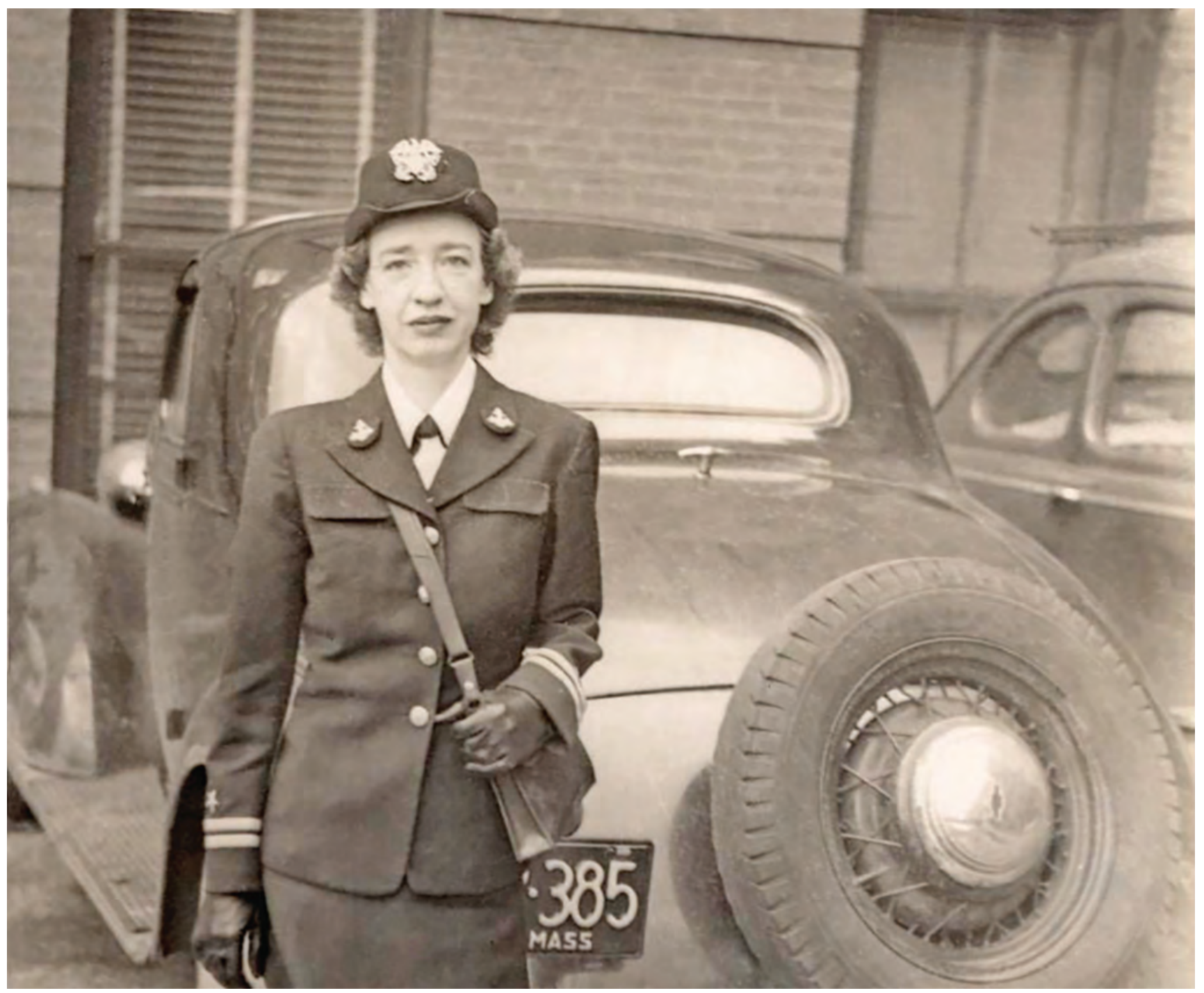

\section{Asher Auel}

Grace Murray Hopper (1906-1992) is well known as a pioneering computer scientist and decorated Naval officer.

Asher Auel is Gibbs Assistant Professor of Mathematics at Yale University. His email address is asher. aue1@ya7e.edu.

Communicated by Notices Associate Editor Angela Gibney.

For permission to reprint this article, please contact:

reprint-permission@ams .org.

DOI: https://doi.org/10.1090/noti1810
Her achievements read as a list of firsts: she was an expert at programming Harvard's Mark I, the first large-scale electromechanical computing machine; she was part of the team who developed the UNIVAC I, the first commercial computer produced in the United States, for which she wrote the first compiler; she created the first English-based data processing language FLOW-MATIC, a principal precursor for $\mathrm{COBOL}$, one of the most important programming languages for business applications; and when she 


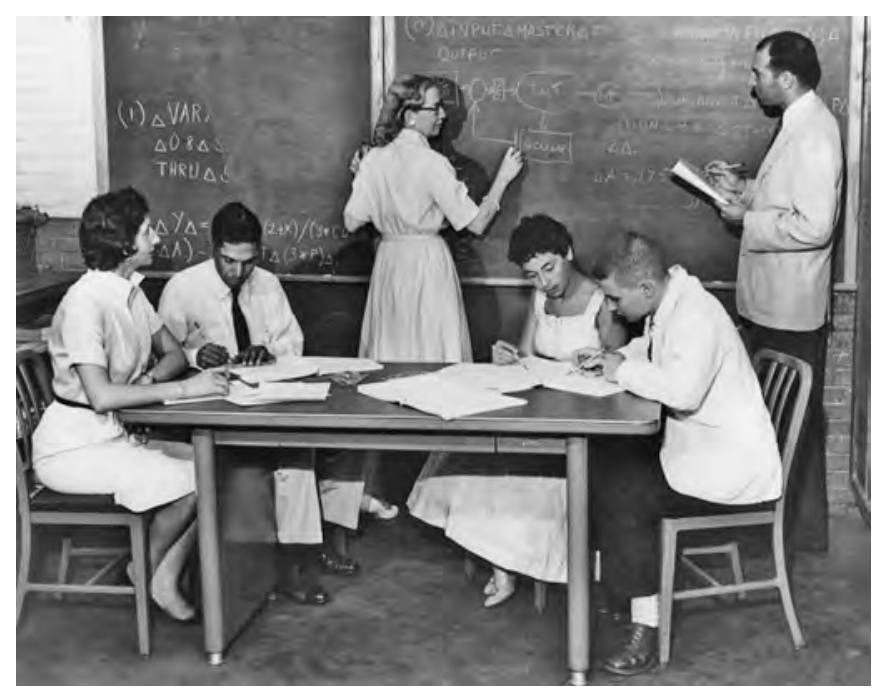

Figure 1. Grace Hopper at the blackboard with students, 1957.

retired from the Navy as a Rear Admiral, at 79 years old, she was the oldest active-duty officer in the entire armed forces. She has been widely lauded for these accomplishments. Named in her honor are: a Naval guided missile destroyer warship; a super computer at the National Energy Research Scientific Computing Center; several buildings and a bridge on Naval bases; a park in Arlington, Virginia; a major yearly convention for women in computer science and technology; several prizes, including an early career award from the Association for Computing Machinery; and a recently renamed residential college at Yale University, among others. Her inspiring story has been the subject of many books and several upcoming film projects.

However, what is often overlooked in accounts of Hopper's life and work is her mathematical legacy. The results of her 1934 Yale PhD thesis advised by Øystein Ore (which are detailed in the section "Thesis Work") are never mentioned. Incorrect characterizations of her graduate work abound; her PhD is routinely cited as being in "mathematics and physics" or "mathematical physics" or "under computer pioneer Howard Engstrom." Her training in pure mathematics and her identity as a mathematician are often minimized or treated as a kind of incongruous early chapter in the story of the "Queen of Code."

But Grace Hopper was most certainly a mathematician. Asked in an interview [30, p. 7] later in her career what she would consider herself, she immediately replied: "Mathematician." Then adding wryly: "A rather degraded one now, because I deal with actual digits instead of letters and formulas." Her broad and rigorous mathematical education constituted what she called her "basic thinking." She was, once and forever, a mathematician: "I've been called an engineer, a programmer, systems analyst and everything under the sun but I still think my basic training

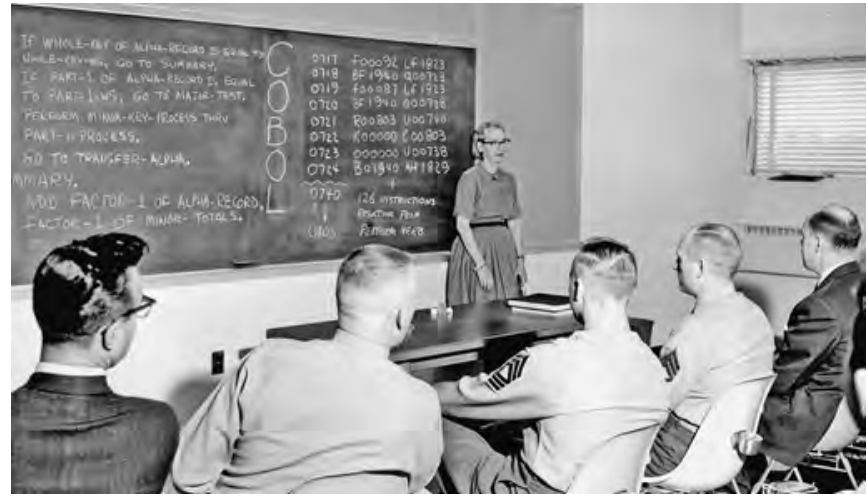

Figure 2. Grace Hopper teaching a COBOL class, 1961.

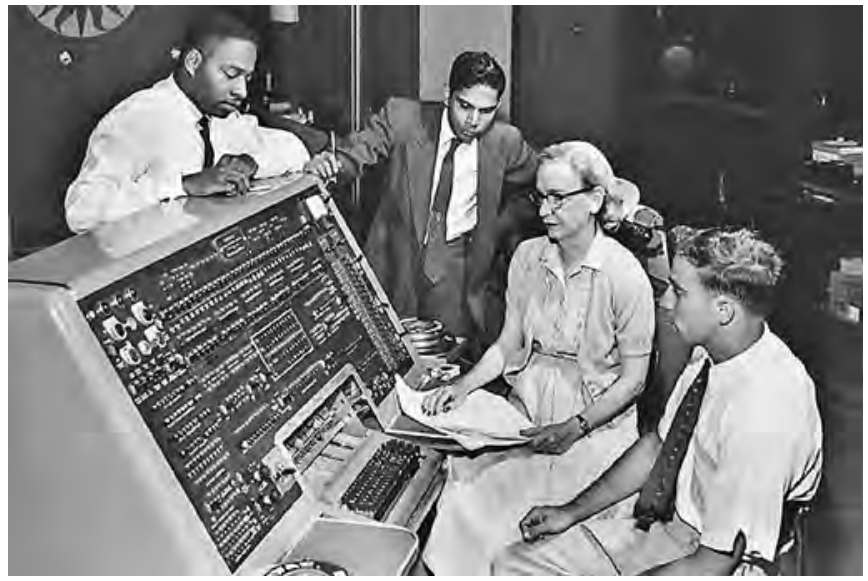

Figure 3. Grace Hopper with programmers at the console of UNIVAC I, 1957.

is mathematics." For the first time, using archival material from Yale University's collections, this article will attempt to illuminate Hopper's foundational mathematical training as well as the specific contributions of her thesis research.

\section{Academic Training}

As both an undergraduate and a graduate student, Grace Hopper pursued a mathematical education. In 1928, she earned her BA from Vassar College, with her coursework primarily in mathematics, and secondarily split between economics and physics. She then enrolled as a graduate student in the Department of Mathematics at Yale University, receiving her MA in 1930 with a thesis titled On Cartesian Ovals and her PhD in 1934 with a dissertation titled New Types of Irreducibility Criteria. Hopper took courses in a wide variety of fields, as her graduate transcript reveals (see Figure 5). Her PhD advisor was Norwegian algebraist $\varnothing y s t e i n$ Ore, who had recently been recruited to Yale and "breathed new life into an aging department" [32, p. 10]. 


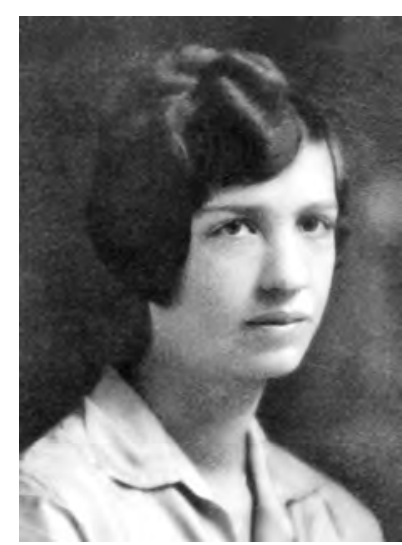

Figure 4. Grace Murray's senior portrait from the Vassar yearbook, 1928.

Notable on Hopper's transcript are Ore's courses on Algebraic Numbers, which had never been offered until his arrival the previous year [32, p. 10]. Hopper was awarded numerous prestigious dissertation fellowships during her years at Yale and was one of the first dozen women (going back to 1895) to earn doctoral degrees in mathematics from the university, see [16]. In 1931, while still a graduate student, Hopper started a faculty position at Vassar, eventually being promoted to assistant professor in 1939 and associate professor in 1944. During the 1941-42 academic year, Hopper was granted a half-time leave from Vassar to take courses with Richard Courant at New York University's Center for Research and Graduate Education (later to become the Courant Institute of Mathematical Sciences).

Numerous distinguished mathematicians can be counted as Hopper's mentors. At Vassar, she studied with Henry Seely White (1861-1943), a prominent American geometer who received his PhD under Felix Klein in 1891 and served as President of the AMS (1906-1908), and Gertrude Smith (1874-1965), whom Hopper declared "taught the best calculus anybody ever taught" [30, p. 21]. At Yale, she was influenced by James P. Pierpont (1866-1938) and was a close contemporary of Howard Engstrom (1902-1962), who received his PhD under Ore in 1929, five years before Hopper, and who eventually returned to Yale to take up a faculty position. In 1941, Engstrom joined the Navy and did foundational work in cryptography; later, he became a deputy director of the National Security Agency, see [12].

Engstrom encouraged several mathematicians, including Hopper and the famous group theorist Marshall Hall, Jr., to join Naval intelligence during World War II. Hall, who received his PhD under Ore in 1936, recalls that while Ore was his "nominal" advisor, he received "far more help and direction" from Engstrom, see [18]. In interviews over the years, Hopper repeatedly describes Engstrom as one of her "instructors." Though no course with Engstrom is listed on Hopper's transcript, his mentorship seems to have

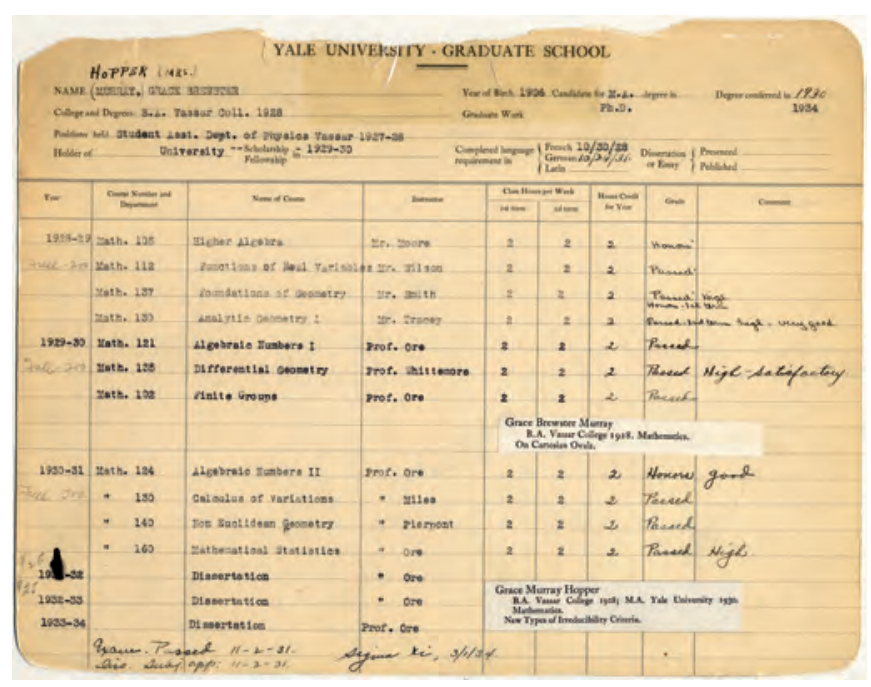

\begin{tabular}{||l|l|l|}
\hline \hline Year & Course Name & Instructor \\
\hline $1928-29$ & $\begin{array}{l}\text { Higher Algebra } \\
\text { Foundations of Real Variables } \\
\text { Foundations of Geometry } \\
\text { Analytic Geometry I }\end{array}$ & $\begin{array}{l}\text { Lucius Terrell Moore } \\
\text { Wallace Alvin Wilson } \\
\text { Percey Franklyn Smith } \\
\text { Joshua Irving Tracey }\end{array}$ \\
\hline $1929-30$ & $\begin{array}{l}\text { Algebraic Numbers I } \\
\text { Differential Geometry } \\
\text { Finite Groups }\end{array}$ & $\begin{array}{l}\text { Øystein Ore } \\
\text { James K. Whittemore } \\
\text { Øystein Ore }\end{array}$ \\
\hline $1930-31$ & $\begin{array}{l}\text { Algebraic Numbers II } \\
\text { Calculus of Variations } \\
\text { Non Euclidean Geometry } \\
\text { Mathematical Statistics }\end{array}$ & $\begin{array}{l}\text { Øystein Ore } \\
\text { Egbert J. Miles } \\
\text { James P. Pierpont } \\
\text { Øystein Ore }\end{array}$ \\
\hline $1931-32$ & Dissertation & $\varnothing$ ystein Ore \\
\hline $1932-33$ & Dissertation & $\varnothing y s t e i n$ Ore \\
\hline $1933-34$ & Dissertation & $\varnothing y s t e i n$ Ore \\
\hline \hline
\end{tabular}

Figure 5. Grace Murray Hopper's original Yale Graduate School transcript lists: her courses and the grades she received (on an Honors/High

Pass/Pass/Fail scale), the dates of her language exams (which years later became fodder for her stories about the interchangeability of written languages [30, pp. 22-23]), as well as her yearly tuition and the date of her election to Sigma $\mathrm{Xi}$, the scientific research honor society. Transcription includes full names of her professors.

been as important for Hopper as it was for Hall. What is clear from the historical record is that Hopper did not "receive her PhD under Engstrom" as several authors have claimed (see [16]), perhaps in an effort to link the early histories of two pioneers in the field of computers. When Hopper enlisted in the Navy, she expected to be assigned to the Communications Supplementary Activity (Navy Communications Annex) in Washington, DC, where Engstrom led a top-secret team building cryptographic computing machines. Though she was eventually assigned to work on the Mark I at Harvard, Hopper and Engstrom stayed life-long friends. 
Several of Ore's graduate students from the early 1930s tackled similar research problems on generalized irreducibility criteria for polynomials. His two male students, Harold Dorwart (PhD 1931) and Casper Shanok (PhD 1933), produced dissertations very close in subject to Hopper's work. Dorwart published a number of articles from his thesis work: in the Annals of Mathematics [7], in the Duke Mathematical Journal [8], and a survey in the American Mathematical Monthly [9, p. 373] that mentions and cites Hopper. Almost immediately following his graduation, Shanok's thesis [45] was published in the Duke Mathematical Journal (though he did not appear to continue in academia). Distressingly, Ore's two female graduate students, Hopper and Miriam Becker (PhD 1934), never published their thesis work at all. Both would, however, go on to long careers (Becker would eventually join the faculty of the City University of New York), even if their earliest work still remains unknown.

As a junior faculty member at Vassar, Hopper was given "all the courses nobody else wanted to teach." But she was such an innovative teacher that classes like technical drawing, trigonometry, calculus, probability, and finite difference method for numerical solutions of differential equations were suddenly popular [30, pp. 16-21]. On top of her demanding teaching schedule of five or six courses, she also audited two courses per year, including basic astronomy, statistical astronomy, geology, philosophy, bacteriology, biology, zoology, plant horticulture, chemistry, physics, economics, and architecture. She also took a course on cryptography sponsored by the Navy [30, p. 27].

Later in life, Hopper would reflect on the "inestimable value" of her broad education as she shaped the new field of computers [30, p. 17]. For example, it was in a chemistry course when she learned the essential concepts of roundoff and truncation errors [27, p. 46]. Her years teaching technical drawing courses enabled her to invent a new method for diagramming the relay timing and associated circuitry (see Figure 6) for the Mark I (formally known as the Automatic Sequence Controlled Calculator) control manual [22], see [30, pp. 32-33]. Hopper summed it up quite neatly in a 1986 interview on The Late Show with David Letterman [21]. During a discussion of her Mark I days, Letterman asked, "Now, how did you know so much about computers then?" "I didn't," Hopper immediately replied, with some bemusement. "It was the first one."

But arguably, it was studying and teaching mathematics -thinking about symbolic language and how to communicate meaning with symbols - that was most pivotal in Hopper's early work on computers. Her invention of various types of early compilers enabled the translation of mathematical statements or English words into computer code.

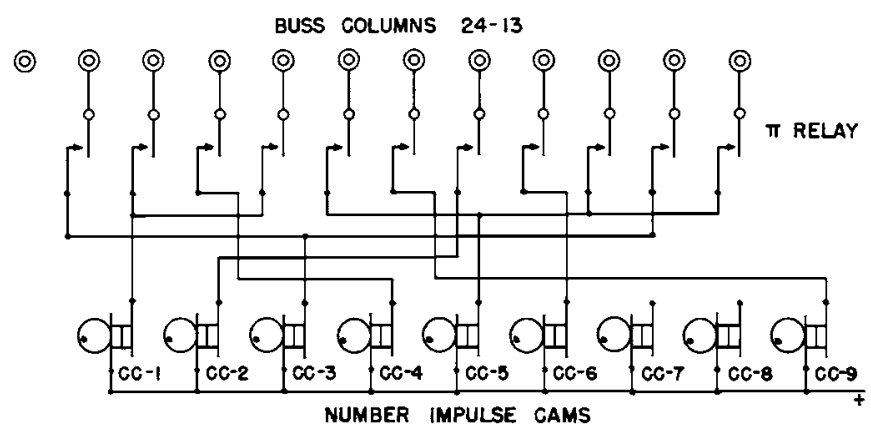

Figure 6. Wiring diagram of a Mark I table relay encoding $\pi[22$, p. 91].

Manipulating symbols was fine for mathematicians but it was no good for data processors who were not symbol manipulators. Very few people are really symbol manipulators. If they are they become professional mathematicians, not data processors. It's much easier for most people to write an English statement than it is to use symbols. So I decided data processors ought to be able to write their programs in English, and the computers would translate them into machine code. [13, p. 3]

One of Hopper's most academically rewarding experiences was taking courses from Richard Courant at New York University in 1941-1942, during her half-time leave funded by a Vassar Faculty Fellowship. Hopper found Courant to be "one of the most delightful people to study with I've ever known in my life." It was, she recalled, "a perfectly gorgeous year. Of course, he scolded me at intervals, just as all of the others did because I kept doing unorthodox things and wanting to tackle unorthodox problems" [30, p. 28]. While there, she studied calculus of variations, differential geometry, and perhaps most fortuitously, she took a government-sponsored defense training course on methods of solutions to partial differential equations involving finite differences taught by Courant, see [30, p. 24] Hopper later learned that her involvement in this course was in her Navy file and was one of the determining factors in her initial assignment: to program Harvard's Mark I, implementing calculations for the war effort including some for John von Neumann's work on the Manhattan Project.

The attack on Pearl Harbor, which took place during her year studying with Courant, forever changed the direction of Hopper's life. Her great grandfather had been in the Navy, and by the summer of 1942, many of Hopper's family members were joining the armed services: her husband (from whom she was already separated) and brother volunteered for the draft; her female cousins joined through the Women's Army Corps (WAC) and the Navy's Women Accepted for Volunteer Emergency Service (WAVES) program; her mother served on the Ration Board; and her retired father went back to work and served on the local Draft 


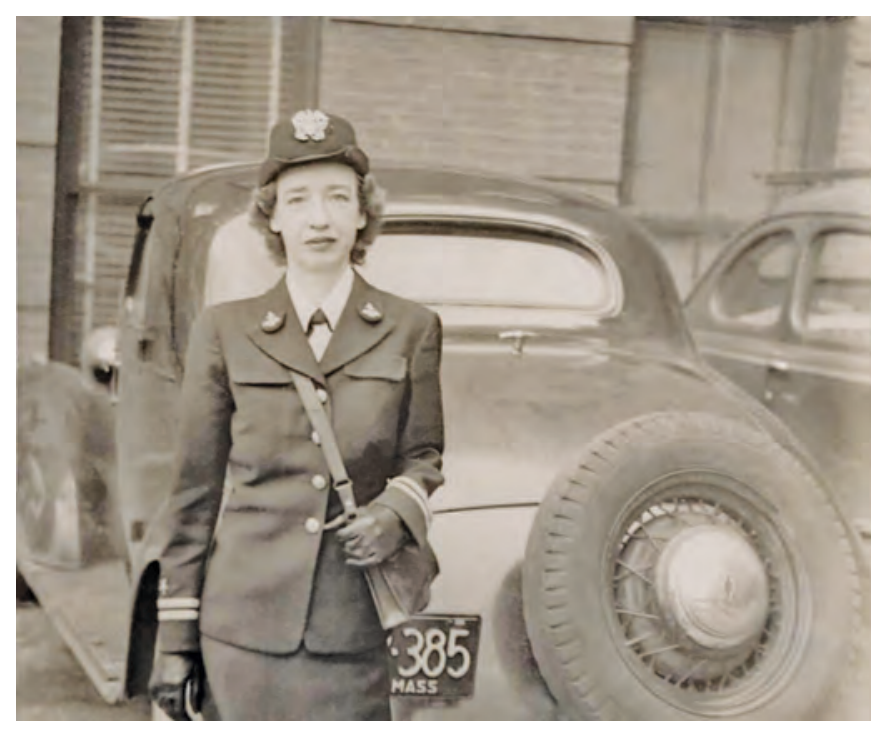

Figure 7. Grace Hopper standing behind a car parked near Cruft Lab, Harvard University, ca. 1945-1947.

Board, see [47, p. 20]. Hopper was eager to enlist in the Navy, but was rejected when she failed to meet the minimum weight requirement for her height and was considered too old for enlistment. In the meantime, she taught an accelerated summer calculus course at Barnard College for women training for war-related posts. But her profession was also an impediment.

Mathematicians were [in] an essential industry and you could not leave your job to go in the services without permission [from both the Navy and one's employer]. You couldn't even transfer jobs without permission... And I was beginning to feel pretty isolated sitting up there, the comfortable college professor-all I was doing was more teaching, and I wanted very badly to get in and so I finally gave Vassar an ultimatum that if they wouldn't release me I would stay out of work for six months because I was going into the Navy, period. [30, p. 25]

Eventually, she obtained a waiver for the weight requirement and a leave of absence from Vassar, and trained at the Naval Reserve Midshipmen's School at Smith College in Northampton, Massachusetts in the spring of 1944. After graduating first in her class, she was commissioned lieutenant junior grade.

On July 2, 1944, Hopper reported for duty at the Bureau of Ships Computation Project at Harvard under the command of Howard Aiken, and began work on the Mark I. Aside from programming the Mark I, and its successor, the Mark II, she was assigned the job of compiling notes about the operation of the Mark I into a book [22]. Hopper

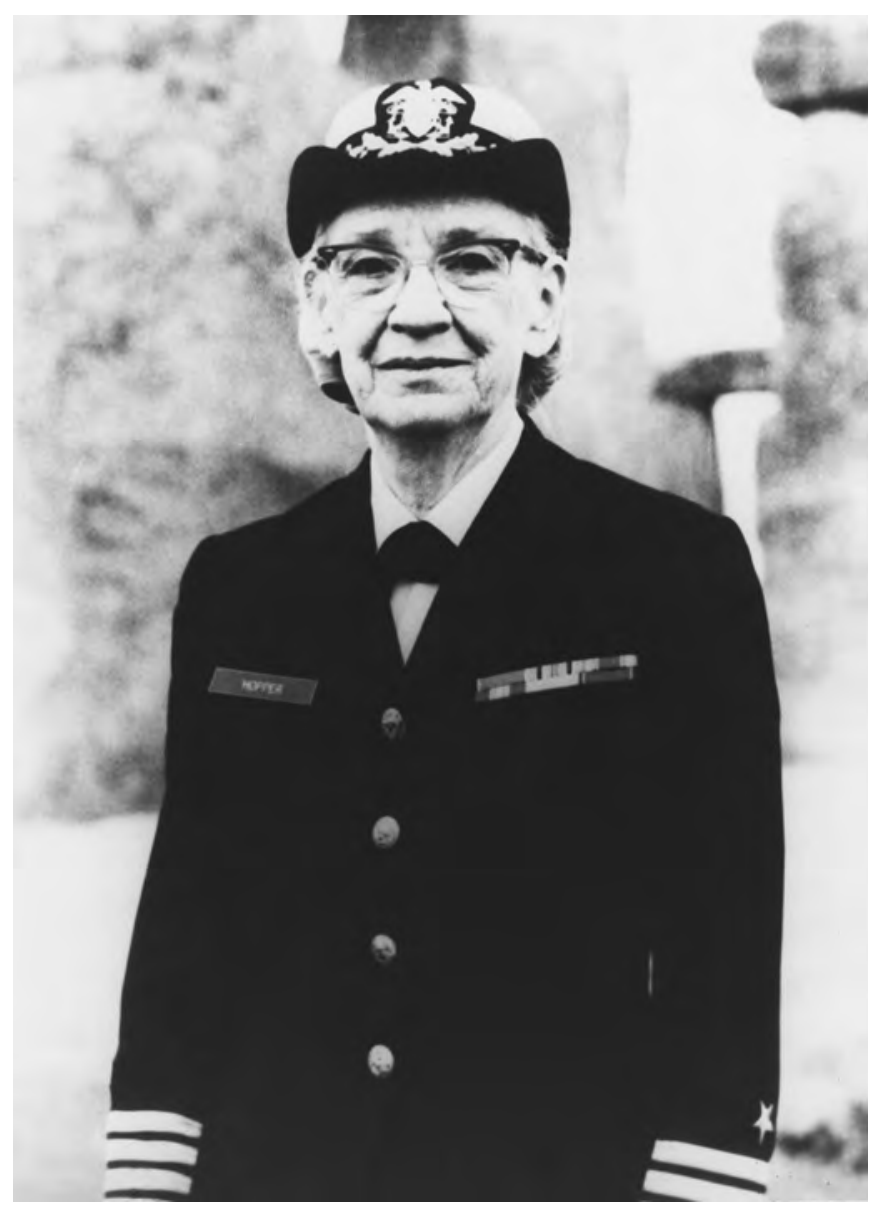

Figure 8. Captain Grace Hopper, ca. 1975.

edited the volume and wrote several of its sections, including an introduction containing the first ever scholarly account of the history and development of calculating machines [22, Chapter I]. "Nobody had done this before," Hopper later said. "[The] history of computers had never been put together." It was, to use her words, "really a job" [30, p. 32].

\section{Thesis Work}

Grace Hopper's PhD thesis work with Øystein Ore concerned irreducibility criteria for univariate polynomials over the field of rational numbers. Though her work was never published, it was presented to an American Mathematical Society meeting on March 30, 1934 in New York with an abstract appearing in the Bulletin of the AMS [20]. The only apparent extant text of her thesis [19] remains in Yale's archives, and a detailed account of her mathematical work has never before appeared in the literature.

In this section, we provide an explanation of Grace Hopper's thesis work, the central theme of which concerns necessary conditions for the irreducibility of univariate polynomials with rational coefficients based on their Newton 
polygons, see the subsection "Irreducibility via Newton polygons." The connection between the decomposability of polynomials and the slopes of their Newton polygons was initiated at the turn of the twentieth century by Dumas [10], with further refinements by Kürschak [26], Ore [35], and Rella [41]. In her work, Hopper obtains new irreducibility criteria by considering an Archimedean analogue of the Newton polygon, see the subsection "Archimedean Newton polygon." While this Archimedean Newton polygon dates back at least to an 1893 paper of Hadamard [17, \$4, p.174], and was later developed further in a 1940 paper of Ostrowski [36, pp. 106, 132] and by Valiron [46, Ch. IX, pp. 193-202], its use for establishing irreducibility criteria seems to be a novel feature of Hopper's work.

Irreducibility of polynomials. A nonconstant polynomial

$$
f(x)=a_{n} x^{n}+a_{n-1} x^{n-1}+\cdots+a_{1} x+a_{0}
$$

whose coefficients $a_{0}, \ldots, a_{n}$ are rational numbers is called irreducible if there is no way to write $f(x)$ as a product $f(x)=g(x) h(x)$ where $g(x)$ and $h(x)$ are themselves nonconstant polynomials with rational coefficients. The study of irreducible polynomials is one of the foundations of modern field theory and often involves quite a bit of number theory as well.

For example, that $x^{2}-2$ is irreducible is equivalent to the classical fact that $\sqrt{2}$ is irrational. More generally, a quadratic polynomial

$$
a x^{2}+b x+c
$$

is irreducible if and only if its discriminant $b^{2}-4 a c$, which appears in the quadratic formula, is not a square.

When $p$ is an odd prime number, that the cyclotomic polynomial

$$
\Phi_{p}(x)=x^{p-1}+x^{p-2}+\cdots+x+1
$$

is irreducible was first proved by Gauss in Disquisitiones Arithmeticae and is related to the arithmetic of the $p$ th roots of unity $e^{2 \pi i k / p}$ and the (non-)constructibility of the regular $p$-gon with compass and straightedge.

In 1929, Schur [44] proved that for $n \geq 1$, the truncated exponential series

$$
1+x+\frac{x^{2}}{2 !}+\cdots+\frac{x^{n}}{n !}
$$

is irreducible with an argument that used a generalization of Bertrand's Postulate, whose original statement-that for any positive integer $k$ there exists a prime number $p$ such that $k<p \leq 2 k$-was conjectured by Bertrand and proved by Chebyshev. This result, and its generalizations, implies the irreducibility of various families of orthogonal polynomials, such as those of Laguerre and Hermite type, see $[9, \S 4]$.
Several standard methods for testing irreducibility are taught in a basic course on field and Galois theory. The most elementary are reduction modulo a prime number and the "rational root test." A more powerful, and yet easy to use, tool is Eisenstein's criterion: assuming that $f(x)$ has integer coefficients, if for some prime number $p$, the coefficients satisfy $p \mid a_{i}$ for all $i \neq n$, as well as $p \nmid a_{n}$ and $p^{2} \nmid a_{0}$, then $f(x)$ is irreducible. In fact, a statement equivalent to Eisenstein's Criterion was first proved by Schönemann [43] in a 1846 paper that Eisenstein even cites in his own paper [11] in 1850, hence the criterion was often called the Schönemann-Eisenstein theorem in literature from the early twentieth century, see [5] for a discussion.

Irreducibility via Newton polygons. In the late nineteenth century and early twentieth century, various generalizations of the Eisenstein criterion, depending on the divisibility properties of the coefficients of $f(x)$, appeared in work of Königsberger, Netto, Bauer, Perron, Ore, and Kahan. Finally, these were all mostly subsumed by an observation of Dumas [10], that such criteria could be rephrased in terms of the irreducibility of the Newton polygon associated to $f(x)$. This history is very well summarized in the historical introduction to Hopper's thesis [19, Chapter I] and in Dorwart's survery article [9].

Given a prime number $p$, we consider the $p$-adic valuation $v_{p}$ on $\mathbb{Q}$. The Newton polygon $N_{p}(f)$ of the polynomial $f(x)=\sum_{i} a_{i} x^{i} \in \mathbb{Q}[x]$ with respect to $p$ is the lower convex hull of the points $\left(i, v_{p}\left(a_{i}\right)\right)$ in $\mathbb{R}^{2}$. We assume that $a_{0} \neq 0$. If $a_{i}=0$ for some $i \geq 0$ then by definition $v_{p}\left(a_{i}\right)=+\infty$, hence for the purposes of taking the lower convex hull, we can ignore such zero coefficients. Intuitively, we can imagine a large rubber band surrounding these points in $\mathbb{R}^{2}$, which each have small nails sticking up from them; as we stretch the rubber band up toward $+\infty$, we obtain the Newton polygon as the lower sequence of line segments formed by the stretched rubber band.

The central insight of Dumas [10, p. 217] is that the Newton polygon $N_{p}(g \cdot h)$ of the product of polynomials $g(x)$ and $h(x)$ is formed by composing the line segments of the Newton polygons $N_{p}(g)$ and $N_{p}(h)$ in order of increasing slope, an operation that we could denote $N_{p}(g) \circ N_{p}(h)$ and call the Dumas sum. This was generalized in [3] and [6], and by many later authors, including to the more general context of (multivariate) polynomials over valued fields.

If the projections to the $x$ - and $y$-axes of the line segments of the Newton polygon of $f(x)$ are denoted $l_{1}, \ldots, l_{r}$ and $k_{1}, \ldots, k_{r}$, respectively, we denote by $e_{i}=\operatorname{gcd}\left(l_{i}, k_{i}\right)$ and write $l_{i}=e_{i} \lambda_{i}$. Then Dumas [10, p. 237] deduces a general irreducibility criterion: $f(x)$ can only have factors 

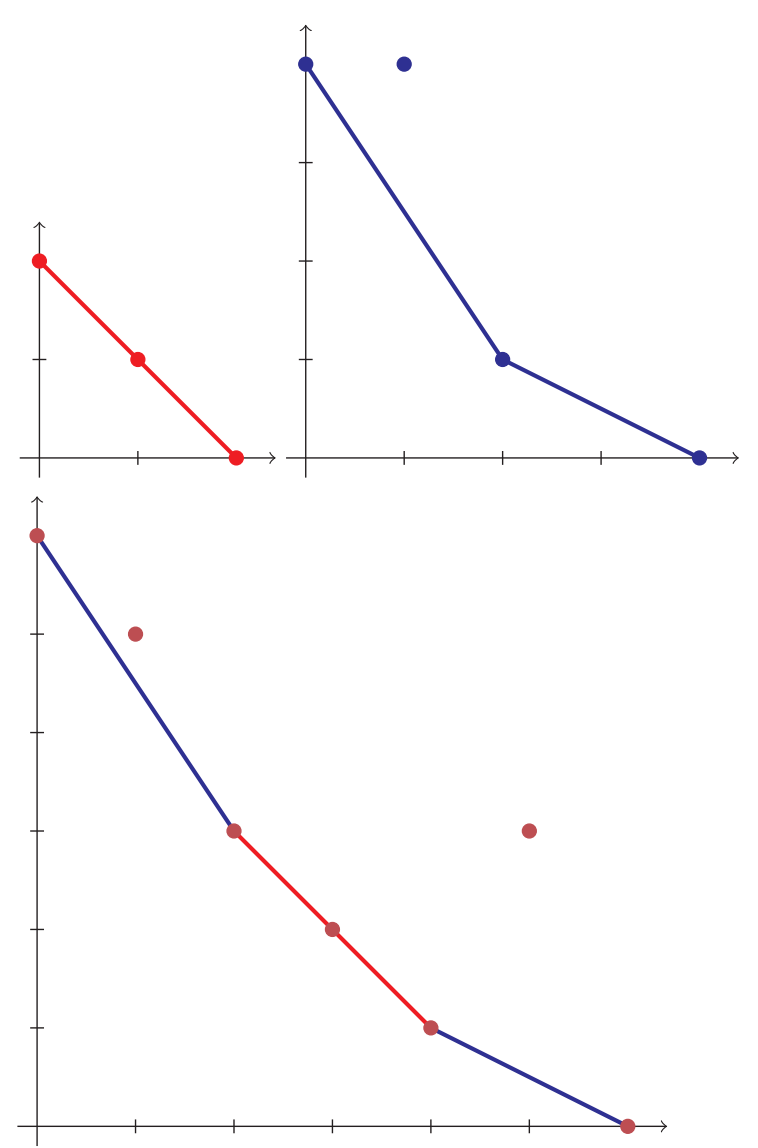

Figure 9. The Newton polygon (with $p=2$ ) of $g(x)=x^{2}+6 x+4$ in red, of $h(x)=x^{4}+2 x^{3}+10 x^{2}+48 x+16$ in blue, and $g(x) h(x)=$

$x^{6}+8 x^{5}+26 x^{4}+116 x^{3}+344 x^{2}+288 x+64$, with sides colored appropriately showing the Dumas sum.

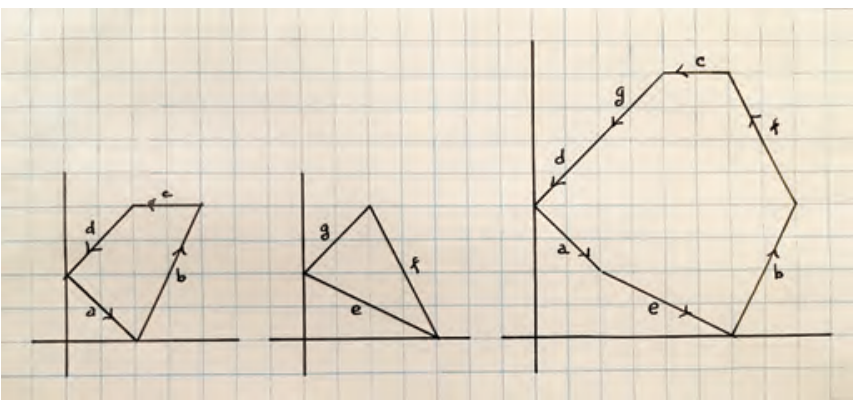

Figure 10. Graphical depiction of the Minkowski sum of two classical Newton polygons of bivariate polynomials. Hand drawn by Grace Hopper [19, p. 24]. of degree $m$ that can be expressed in the form

$$
m=\sum_{i=1}^{r} \mu_{i} \lambda_{i}
$$

where $\mu_{i} \in\left\{0,1, \ldots, e_{i}\right\}$ for each $1 \leq i \leq r$.

For example, if $N_{p}(f)$ consists of a single line segment that does not pass through any lattice point in the plane, then $f(x)$ is irreducible. This immediately gives the Eisenstein criterion. Generalizations and refinements of this idea were developed by Fürtwangler, Kürschak, and Ore, see [19, Chapter I, \$4].

The classical Newton polygon associated to a bivariate polynomial $f(x, y)$ over a field, defined as the convex hull of the weight vectors $(i, j)$ in $\mathbb{R}^{2}$ of all monomials $x^{i} y^{j}$ appearing with nonzero coefficients in $f(x, y)$, first appears in a 1676 letter from Newton to Oldenberg [23] and was well known to Newton and his followers throughout the 18 th and 19th century, cf. [4, Chapter XXX, \$24, Historical Note]. Though it must have been well known, the observation that the classical Newton polygon of a product of polynomials is the Minkowski sum (see Figure 10) of their classical Newton polygons does not seem to be clearly enunciated in the literature until the theses of Shanok [45, \$2, p. 103, footnote 3] and Hopper [19, Chapter II, §1].

Archimedean Newton polygon. A completely different type of irreducibility criterion depending on the relative magnitudes of the absolute values of the coefficients was introduced by Perron [40]. (We now assume that $f(x)$ is a monic polynomial with coefficients in $\mathbb{Z}$.) These criteria depend on the following simple observation: if $n-1$ of the (complex) roots of $f(x)$ have absolute value $<1$, then $f(x)$ is irreducible. Indeed, if $f(x)$ has a nonconstant factor (which by Gauss's Lemma can be taken to be monic with integer coefficients), then all of its roots will have absolute value $<1$, but their product is the (integral) constant term, a contradiction. The resulting irreducibility criterion is, letting $A=\left|a_{0}\right|+\cdots+\left|a_{n-1}\right|+1$ : if the coefficients satisfy $\left|a_{n-1}\right|>\frac{1}{2} A$, then $f(x)$ is irreducible. There is a similar criterion if all but a pair of complex conjugate roots have absolute value $<1$.

To take into account the relative magnitudes of the coefficients, Hopper [19, Chapter III] considers an Archimedean Newton polygon associated to a polynomial $f(x)$ with complex coefficients. Define $N_{\infty}(f)$ to be the lower convex hull of the set of points $\left(i,-\log \left|a_{i}\right|\right)$ in $\mathbb{R}^{2}$. As before, if $a_{i}=0$ for some $0<i<n$, then $-\log \left|a_{i}\right|=+\infty$, so can be ignored for the purposes of taking the lower convex hull. (In fact, Hopper defines the mirror image of this polygon.) This is a natural generalization of the Newton polygon with respect to a prime $p$ considered above. Indeed, the negative absolute logarithm can be considered as an 
Archimedean analogue of a valuation; writing $v_{\infty}(x)=$ $-\log |x|$, then $|x|=e^{-v_{\infty}(x)}$ is in analogy with the nonArchimedean $p$-adic absolute value $|x|_{p}=p^{-v_{p}(x)}$.

Later in the twentieth century, the Archimedean Newton polygon was, in various guises, used in a variety of contexts, including: by Khovansky [25] (cf. [42]) in an algebraic reformulation of his study of exponential equations and eventually for combinatorial invariants attached to divisors on algebraic varieties; by Mueller and Schmidt [33], [34] for bounding the number of solutions to Thue equations; and by Passare and his collaborators (see e.g., [38], [37, \$2.1], [1]) and Mikhalkin (see e.g., [39]) in the theory of amoebas and in tropical geometry. The genesis of the Archimedean Newton polygon going back to Hadamard, as well as most of these later uses, stems from the fact that its geometry is related to the absolute values of the roots of the polynomial.

Taking a different approach, Hopper [19, Chapter III] studies the Archimedean Newton polygon of a product of polynomials, in analogy with Dumas's result in the nonArchimedean case: how do $N_{\infty}(g)$ and $N_{\infty}(h)$ compare with $N_{\infty}(g \cdot h)$ ? Hopper remarks that if the analogue of Dumas's product result held for $N_{\infty}$, then irreducibility criteria such as Perron's, which depend on the relative magnitude of the coefficients, would follow immediately. However, $-\log |x|$ is not a valuation as there is an error term in relating $-\log |x+y|$ with $\min (-\log |x|,-\log |y|)$, hence such an exact product formula is not expected. However, Hopper goes on to prove bounds on how far apart $N_{\infty}(g \cdot h)$ can be from $N_{\infty}(g) \circ N_{\infty}(h)$. To state these bounds, if $f(x) \in \mathbb{C}[x]$ is a polynomial of degree $n \geq 1$, we consider $N_{\infty}(f)$ as a piecewise-linear function of $t$ on the real interval $[0, n]$.

Theorem 1 (Hopper [19, Chapter III, §3-5, pp. 33-38]). Let $g(x), h(x) \in \mathbb{C}[x]$ be monic polynomials and $n=$ $\operatorname{deg}(g)+\operatorname{deg}(h)$. Then

$$
\begin{aligned}
-\log \left(1+\frac{n}{2}\right) & \leq\left(N_{\infty}(g \cdot h)(t)-\left(N_{\infty}(g) \circ N_{\infty}(h)\right)(t)\right. \\
& \leq \log \left(3 \cdot 2^{t(n-t)}\right)
\end{aligned}
$$

for all $t \in[0, n]$.

More precisely, Hopper establishes an upper bound, as in Theorem 1, that depends on the sharpness of the bends in $N_{\infty}(g) \circ N_{\infty}(h)$, defined as the (exponential of the) ratio of slopes of consecutive sides. Near very sharp bends, the two polygons are very close; the careful analysis [19, Chapter III, \$5] of bends with small sharpness gives the upper bound. She remarks that the "result can however probably be considerably improved upon" due to certain estimates employed in the proof [19, p. 38].
The Newton-Hopper polygon. In [19, Chapter II, §2], Hopper introduces a new construction of a convex polygon associated to a monic polynomial with integer coefficients that takes into account both the divisibility (with respect to a fixed prime $p$ ) and the magnitudes of the coefficients. We call this the Newton-Hopper polygon $N H_{p}(f)$ associated to $f(x)=\sum_{i} a_{i} x^{i} \in \mathbb{Z}[x]$. It is defined by writing

$$
f(x)=\sum_{i} \sum_{j} r_{i j} p^{j} x^{i}
$$

where $r_{i j} \neq 0$ and satisfy $-p<r_{i j}<p$, and then taking the convex hull of the points $(i, j)$ in $\mathbb{R}^{2}$. This construction yields a convex polygon whose "lower half" is $N_{p}(f)$ and whose "upper half" is the upper convex hull of the points $\left(i,\left\lfloor\log _{p}\left|a_{i}\right|\right\rfloor\right)$, so that the upper half is approximately $-N_{\infty}(f)$. The analogous bounds in Theorem 1 hold for the upper half of the Newton-Hopper polygon of a product.

Hopper's strategy [19, Chapter IV] is then to start with a polynomial $f(x) \in \mathbb{Z}[x]$, plot $N H_{p}(f)$ (in black ink), and then plot (in red and blue ink) the limits of the upper and lower bounds in Theorem 1 away from $N H_{p}(f)$. Finally, if one can verify that each possible polygon within the region bounded between the (red and blue) limits cannot be decomposed as a Dumas sum of Newton-Hopper polygons (where we formally apply Dumas composition to the upper half and lower half separately) of lower degrees, then $f(x)$ must be irreducible. This observation provides new irreducibility criteria that simultaneously generalize those depending on the divisibility and the magnitudes of the coefficients.

Hopper then proceeds with a careful analysis of various general situations in which this occurs, and then produces families of sparse polynomials that satisfy these criteria. Some of her families in [19, Chapter IV, \$5] cannot be proven to be irreducible solely using either divisibility properties or relative magnitude properties of the coefficients on their own. For example, the polynomial

$$
f(x)=x^{7} \pm\left(p^{11}+p\right) x^{5} \pm p^{4},
$$

for any prime $p>3 \cdot 2^{49 / 4}>14,612$ (e.g., $p=14,621$ is the first such prime), is irreducible. Similarly, the polynomial

$$
f(x)=x^{9} \pm\left(p^{6}+p\right) x^{3} \pm\left(p^{9}+p^{3}\right) x^{2} \pm p^{3},
$$

for any $p>3 \cdot 2^{81 / 4}>3,740,922$ (e.g., $p=3,740,923$ is the first such prime) is irreducible, see Figure 11. For all primes $p$ below these bounds, a computer algebra system can verify the irreducibility of the above polynomials. Also, the following infinite family of polynomials

$$
f(x)=x^{n} \pm k x^{2} \pm l p^{2 v+1},
$$




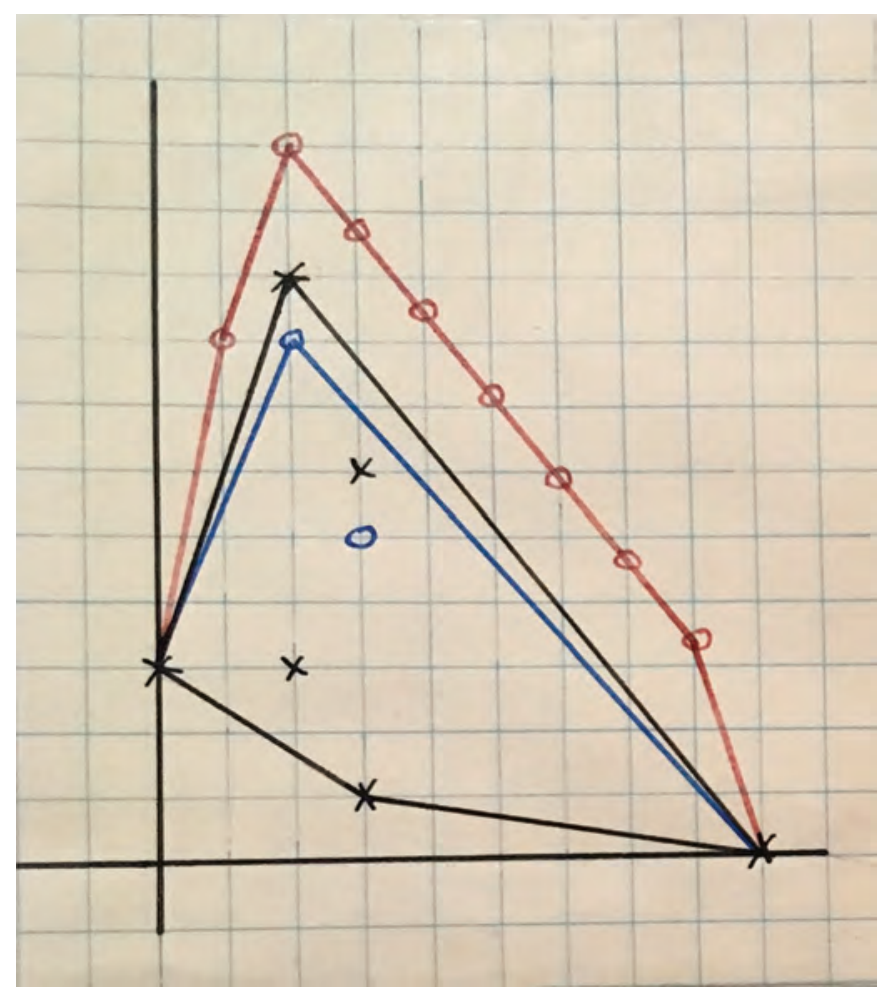

Figure 11. The Newton-Hopper polygon of the polynomial (1), in black, with the upper and lower bounds in Theorem 1 in red and blue, respectively. Hand drawn by Grace Hopper [19, p. 55].

where $n \geq 3, v \geq 3,0<k<p^{2(v-2)}, p \nmid k, 0<l<p$, and $p>3 \cdot 2^{n^{2} / 4}$, are all irreducible. Similarly, the following infinite family of polynomials

$$
f(x)=x^{n} \pm k p x \pm m p^{v}
$$

where $n \geq 2, v \geq 4,0<k<p^{2(v-2)}, 0<m<p^{v-3}$, $p \nmid k m$, and $p>3 \cdot 2^{n^{2} / 4}$, are all irreducible.

ACKNOWLEDGMENTS. The author would like to thank retired Yale Mathematics librarian Paul Lukasiewicz for introducing him to the story of Grace Hopper; head of Grace Hopper College, Julia Adams, for her support and stimulating conversations; Grace Hopper's nephew and great-niece, Roger and Deborah Murray, for their encouragement of this article; Yale University archivist, Michael Lotstein, for his tireless assistance in locating Hopper-related archival material; Vassar College associate registrar, Kathleen Giblin, for providing and deciphering Hopper's college transcript; Sam Payne for productive mathematical discussions; and Jennifer Raab for her generous help during the preparation of this article. Finally, the author is grateful to Judy Green for answering many questions about Hopper's history, and for her pioneering study with
Jeanne LaDuke [13], [14], which is an indispensable resource on Hopper's life and work.

\section{References}

[1] Avendaño M, Kogan R, Nisse M, Rojas JM, Metric estimates and membership complexity for Archimedean amoebae and tropical hypersurfaces, Journal of Complexity 46 (2018), 45-65. MR3774347

[2] Beyer K, Grace Hopper and the Invention of the Information Age, MIT Press, Cambridge, MA, 2009.

[3] Blumberg $\mathrm{H}$, On the factorization of expressions of various types, Trans. Amer. Math. Soc. 17 (1916), no. 4, 517544. MR1501056

[4] Chrystal G, Algebra, Part II, 2nd ed., Adam \& Charles Black, London, 1900. MR0121327

[5] Cox DA, Why Eisenstein proved the Eisenstein criterion and why Schönemann discovered it first, American Mathematical Monthly 118 (2011), no. 1, 3-31. MR2795943

[6] Dines LL, A theorem on the factorization of polynomials of certain types, Bulletin of the AMS 29 (1923), 440.

[7] Dorwart HL, Ore Ø, Criteria for the irreducibility of polynomials, Ann. of Math. (2) 34 (1933), no. 1, 81-94; erratum Ann. of Math. (2) 35 (1934), no. 1, 195. MR1503098

[8] Dorwart HL, Concerning certain reducible polynomials, Duke Math. J. 1 (1935), no. 1, 70-73. MR1545865

[9] Dorwart HL, Irreducibility of polynomials, Amer. Math. Monthly 42 (1935), no. 6, 369-381. MR1523399

[10] Dumas G, Sur quelques cas d'irréductibilité des polynômes coefficients rationnels, Journal de Mathématiques Pures et Appliquées (6) 2 (1906), 191-258.

[11] Eisenstein G, Über die Irreductibilität und einige andere Eigenschaften der Gleichung, von welcher die Theilung der ganzen Lemniscate abhängt, Journal für die reine und angewandte Mathematik 39 (1850), 160-179. MR1578663

[12] Engstrom HT, Scientist, Was 59: One of the Developers of Univac Computer Dies, New York Times, 10 March 1962, p. 21.

[13] Gilbert L, Moore G, Particular Passions: Grace Murray Hopper, chapter in Women of Wisdom: Talks With Women Who Shaped Our Times, Lynn Gilbert Inc., 1981.

[14] Green J, LaDuke J, Pioneering Women in American Mathematics: The Pre-1940 PhD's, History of Mathematics, vol. 34, American Mathematical Society, Providence, RI, 2008. MR2464022

[15] Green J, LaDuke J, Supplementary Material for Pioneering Women in American Mathematics: The Pre-1940 PhD's, available at http://www.ams.org/publications/ authors/books/postpub/hmath-34. MR2919139

[16] Green J, LaDuke J, Letter to the Editor, Isis 102 (2011), no. 1, pp. 136-137. MR1983738

[17] Hadamard J, Étude sur les propriétés des fonctions entières et en particulier d'une fonction considérée par Riemann, Journal de Mathématiques Pures et Appliquées (4) 9 (1893), 171-216. MR0220564

[18] Hall M Jr, Mathematical Biography: Marshall Hall Jr., in A Century of Mathematics in America, Part I, History of Mathematics, vol. 1, Peter Duran, Richard Askey, Uta 
C. Merzbach, eds., American Mathematical Society, Providence, RI, 1988, pp. 367-374. MR1563496

[19] Hopper GM, New types of irreducibility criteria, PhD dissertation, Yale University, May 1934, available at http://math.yale.edu/grace-murray-hopper. MR2936986

[20] Hopper GM, Ore Ø, New types of irreducibility criteria, Bull. Amer. Math. Soc. 40 (1934), abstract no. 126, 216. MR2936986

[21] Late Night with David Letterman, season 5, episode 771, October 2, 1986, National Broadcasting Company, New York, NY.

[22] A Manual of Operation for the Automatic Sequence Controlled Calculator, by the staff of Computation Laboratory, Annals of the Computation Laboratory of Harvard University, vol. 1, Harvard University Press, Cambridge, MA, 1946. MR0020856

[23] Newton I, letter to Henry Oldenburg dated 1676 Oct 24, in The Correspondence of Isaac Newton: Volume 2, 16761687, pp. 126-127, Cambridge University Press, 1960. MR551872

[24] Grace Murray Hopper 1906-1992, Notices Amer. Math. Soc. 39 (1992), 320. MR1153173

[25] Hovansky A, Sur les racines complexes des systèmes 'déquations algébriques comportant peu de termes, $C$. $R$. Acad. Sci. Paris Ser. I Math. 292 (1981), no. 21, 937-940. MR625726

[26] Kürschák J, Irreduzible Formen, Journal für die Mathematik 152 (1923), 180-191. MR1581009

[27] Grace Murray Hopper (1906-1992), interview by Beth Luebbert and Henry Tropp, 5 July 1972, Computer Oral History Collection, Archives Center, National Museum of American History, Smithsonian Institution, transcript available at http://amhistory.si .edu/archives/ AC0196_hopp720507.pdf

[28] MacLane S, A construction for absolute values in polynomial rings, Trans. Amer. Math. Soc. 40 (1936), no. 3, 363395. MR1501879

[29] Mathews S, Mogensen M, Grace Brewster Murray Hopper, student paper for Appalachian State University course Women and Minorities in Math, taught by Sarah J. Greenwald, Spring 2001, available at http://www.cs.appstate.edu/ sjg/wmm/ student/hopper/hopperp.htm.

[30] Grace Murray Hopper (1906-1992), interview by Uta C. Merzbach, July 1968, Computer Oral History Collection, Archives Center, National Museum of American History, Smithsonian Institution, transcript available at http: //amhistory.si .edu/archives/ AC0196_hopp680700.pdf.

[31] Voice of America interviews with eight American women of achievement: Grace Hopper, Betty Friedan, Nancy Landon Kassebaum, Mary Calderone, Helen Thomas, Julia Montgomery Walsh, Maya Angelou, Nancy Clark Reynolds, interviews by Chantal Mompoullan, Voice of America, United States Information Agency, Washington, DC, 1985.

[32] Mostow GD, Science at Yale: Mathematics, Yale University Press, New Haven, CT, 2001.
[33] Mueller J, Schmidt WM, Thue's equation and a conjecture of Siegel, Acta Math. 160 (1988), no. 3-4, 207-247. MR945012

[34] Mueller J, Schmidt WM, On the Newton Polygon, Monatshefte für Mathematik, 113 (1992), no. 1, 33-50. MR1149059

[35] Ore O, Zur Theorie der Irreduzibilitätskriterien, Mathematische Zeitschrift 18 (1923), 278-288. MR1544631

[36] Ostrowski A, Recherches sur la méthode de Graeffe et les zéros des polynomes et des séries de Laurent, Acta Math. 72 (1940), 99-155. MR0001944

[37] Passare MJ, Rojas M, Shapiro B, New multiplier sequences via discriminant amoebae, Mosc. Math. J. 11 (2011), no. 3, 547-560. MR2894430

[38] Passare $M$, Rullgård $H$, Amoebas, Monge-Ampère measures, and triangulations of the Newton polytope, Duke Math. J. 121 (2004), no. 3, 481-507. MR2040284

[39] Mikhalkin G, Enumerative tropical algebraic geometry in $\mathbb{R}^{2}$, Journal of the American Mathematical Society 18 (2005), no. 2, 313-377. MR2137980

[40] Perron O, Neue Kriterien für die Irreduzibilität algebraischer Gleichungen, Journal für Mathematik 132 (1907), 288 307. MR1580727

[41] Rella T, Ordnungsbestimmungen in Integritätsbereichen und Newtonische Polygone, Journal für die Mathematik 158 (1927), 33-48. MR1581128

[42] Risler JJ, Complexité Géométrie Réelle, Sém. Bourbaki (1984-85), no. 637, Astérisque 133-134 (1986), 89-100.

[43] Schönemann T, Von denjenigen Moduln, welche Potenzen von Primzahlen sind, Journal für die reine und angewandte Mathematik 32 (1846), 93-118. MR1578516

[44] Schur I, Einige Sätze über Primzahlen mit Anwendungen auf Irreduzibilitätsfragen I, Sitzungsberichte Preuss. Akad. Wiss. Phys.-Math. Klasse 14 (1929), 125-136. Also in Gesammelte Abhandlungen, Band III, 140-151. MR0462893

[45] Shanok C, Convex polyhedra and criteria for irreducibility, Duke Math. J. 2 (1936), no. 1, 103-111. MR1545909

[46] Valiron G, Fonctions analytiques, Presses Universitataires de France, Paris, 1954. MR0061658

[47] Williams K, Grace Hopper: Admiral of the Cyber Sea, Naval Institute Press, Annapolis, MD, 2004.

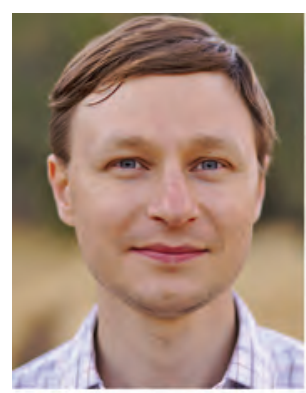

Asher Auel 
FEATURED TITLE FROM HINDUSTAN
BOOK AGENCY

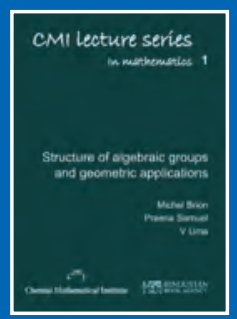

Structure of Algebraic Groups and Geometric Applications

Michael Brion, University of Grenoble I, Martin d'Heres, France, Preena

Samuel, Institute of Mathematical Science, Tamilnadu, India, and V. Uma, Indian Institute of Technology, Chennai, India

This book originates from a series of 10 lectures given by Michel Brion at the Chennai Mathematical Institute during January 2011. The book presents Chevalley's theorem on the structure of connected algebraic groups, over algebraically closed fields, as the starting point of various other structure results developed in the recent past.

Chevalley's structure theorem states that any connected algebraic group over an algebraically closed field is an extension of an abelian variety by a connected affine algebraic group. This theorem forms the foundation for the classification of anti-affine groups which plays a central role in the development of the structure theory of homogeneous bundles over abelian varieties and for the classification of complete homogeneous varieties. All these results are presented in this book.

Hindustan Book Agency; 2012; 128 pages; Softcover; ISBN: 978-93-80250-46-5; List US\$48; AMS members US\$38.40; Order code HIN/55

\footnotetext{
$\longrightarrow$
}

Titles published by the Hindustan Book Agency (New Delhi, India) include studies in advanced mathematics, monographs, lecture notes, and/or conference proceedings on current topics of interest.

\section{Discover more books at bookstore.ams.org/hin.}

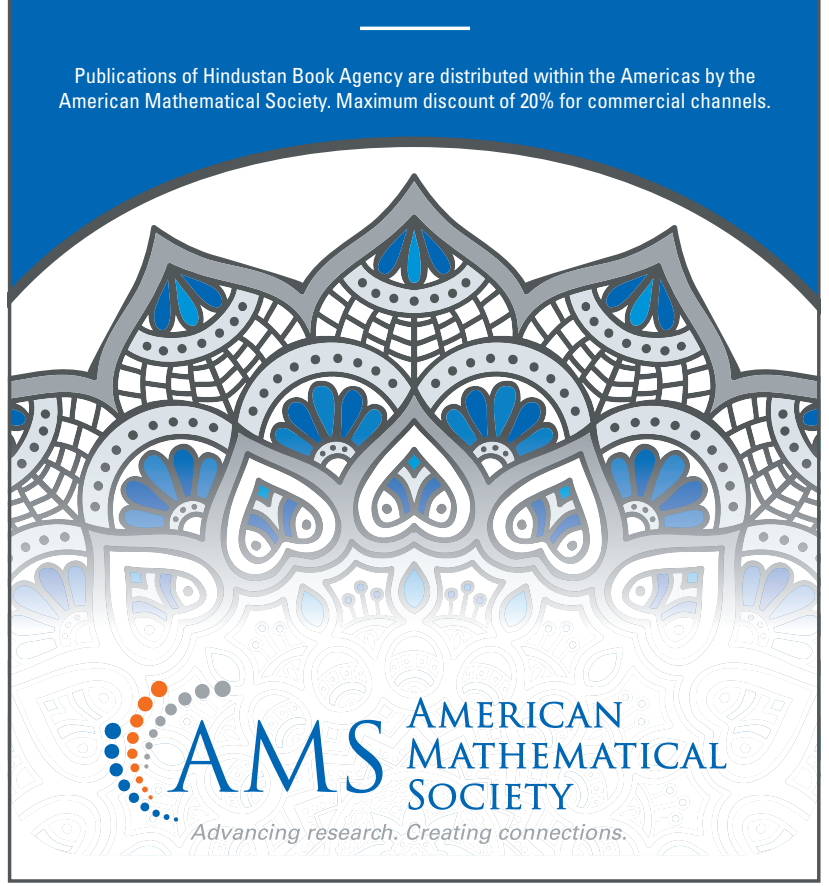

\section{Credits}

Figures 1 and 2, Hagley Museum and Library "Sperry Corporation, UNIVAC Division" collection of photographs and audiovisual materials. Reproduction is courtesy of the Unisys Corporation.

Figures 3 and 8 are courtesy of the Division of Medicine and Science, National Museum of American History, Smithsonian Institution.

Figure 4 is courtesy of Archives and Special Collections, Vassar College Library.

Figure 5 is courtesy of Graduate School of Arts and Sciences, Yale University, Student Records (RU 262), Manuscripts and Archives, Yale University Library. Reproduction in consultation with family representatives Roger and Deborah Murray.

Figure 6 is courtesy of Harvard University Press. Reproduction authorized and permitted upon publication by the President and Fellows of Harvard College.

Figure 7 is courtesy of Grace Murray Hopper Collection, Archives Center, National Museum of American History, Smithsonian Institution.

Figure 9 was created by the author using TikZ.

Figures 10 and 11 are courtesy of Manuscripts and Archives, Yale University Library. Reproduction of details from Grace Murray Hopper's PhD dissertation [19] in consultation with family representatives Roger and Deborah Murray.

Author photo was taken by Joe Rabinoff in Salt Lake City, Utah, July 2015. Reproduction is courtesy of Joe Rabinoff. 